\title{
SEBASTIANA DE OXÓSSI (1933-2019) MÃe Grande Kilombola GuerreiRa do Futuro AnCEStRal
}

Luciana de Oliveira

Fernanda de Oliveira²

[Sebastiana Geralda Ribeiro da Silva, 5 de dezembro de 1933-6 de junho de 2019]

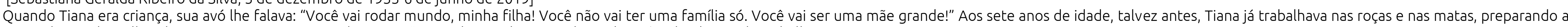
terra, plantando, colhendo. Como nos contou, naquele tempo "não tinha escola, não tinha nada... só tinha direito de trabalhar".

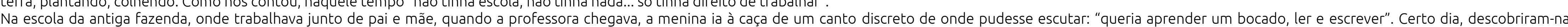
escondida e a proibiram de se aproximar da escola enquanto as aulas aconteciam. Desde quando Tiana começou a "se entender por gente", o "mundo dos brancos" lhe aparecia assim, cheio de abusos e privações.

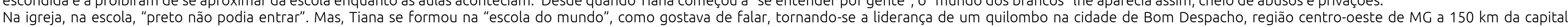

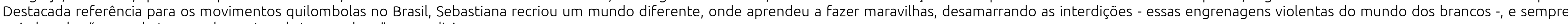
guiada pelos "povos do tempo, das matas, da terra e do ar", como dizia.

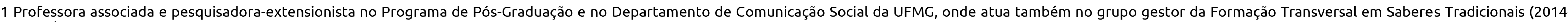

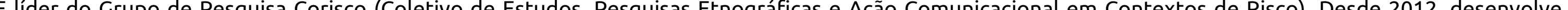

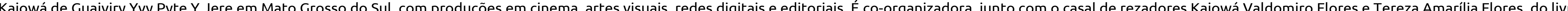
Kaive (2020) Email: luciana.lucyoli@gmail.com

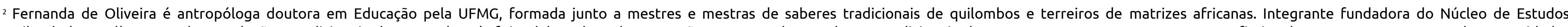

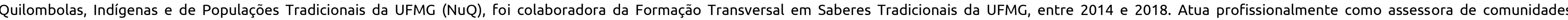
tradicionais e consultora em estudos relativos a direitos territoriais, patrimônio cultural, cultura e educação. 


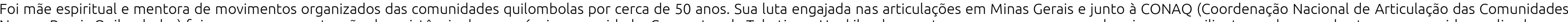

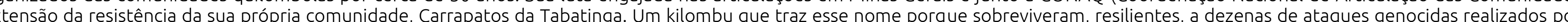

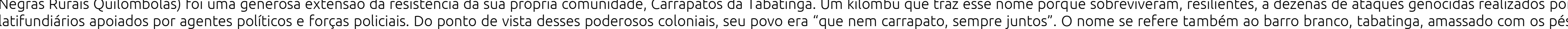
para a construção das moradias quilombolas.

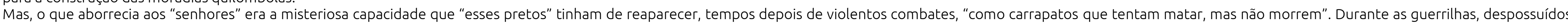

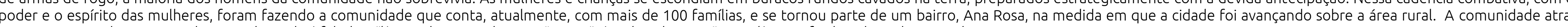
muitos pesquisadores por ser lugar onde ainda é falada a "língua do negro da Costa", ou a "gíria de Tabatinga", uma língua afro-brasileira de matriz banto.

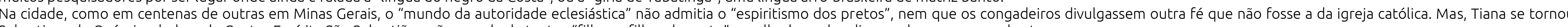

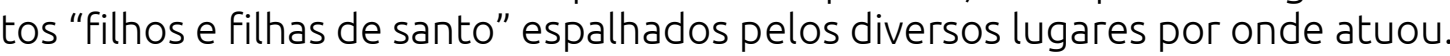

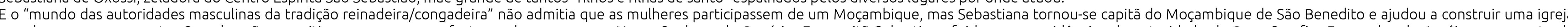

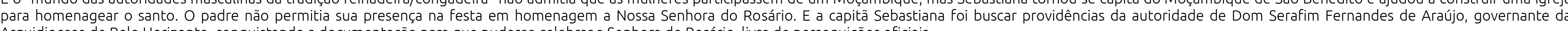
Arquidiocese de Belo Horizonte, conquistando a documentação para que pudesse celebrar a Senhora do Rosário, livre de perseguições oficiais.

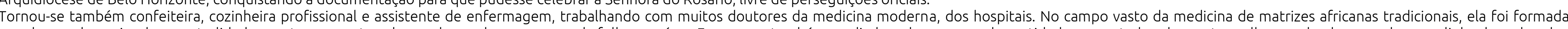

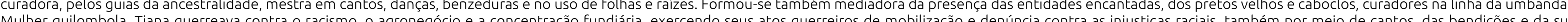

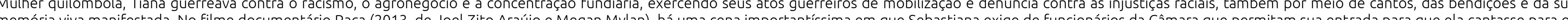

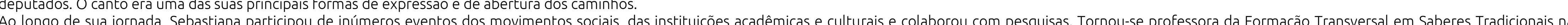
UFMG em 2014, dando oportunidade para que dezenas de estudantes pudessem conhecer uma parcela fundamental da "verdadeira história do Brasil", como dizia a professora contra-colonial.

$* * *$

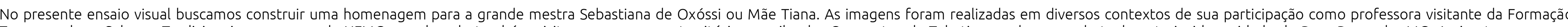

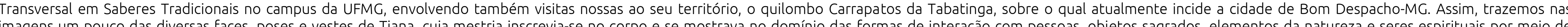

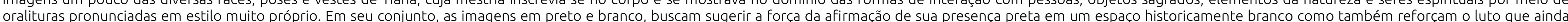
elaboramos e as saudades que sua partida para um novo ciclo vital nos legou. O ensaio-homenagem se completa por uma breve rememoração poético-política de sua biografia notável. 


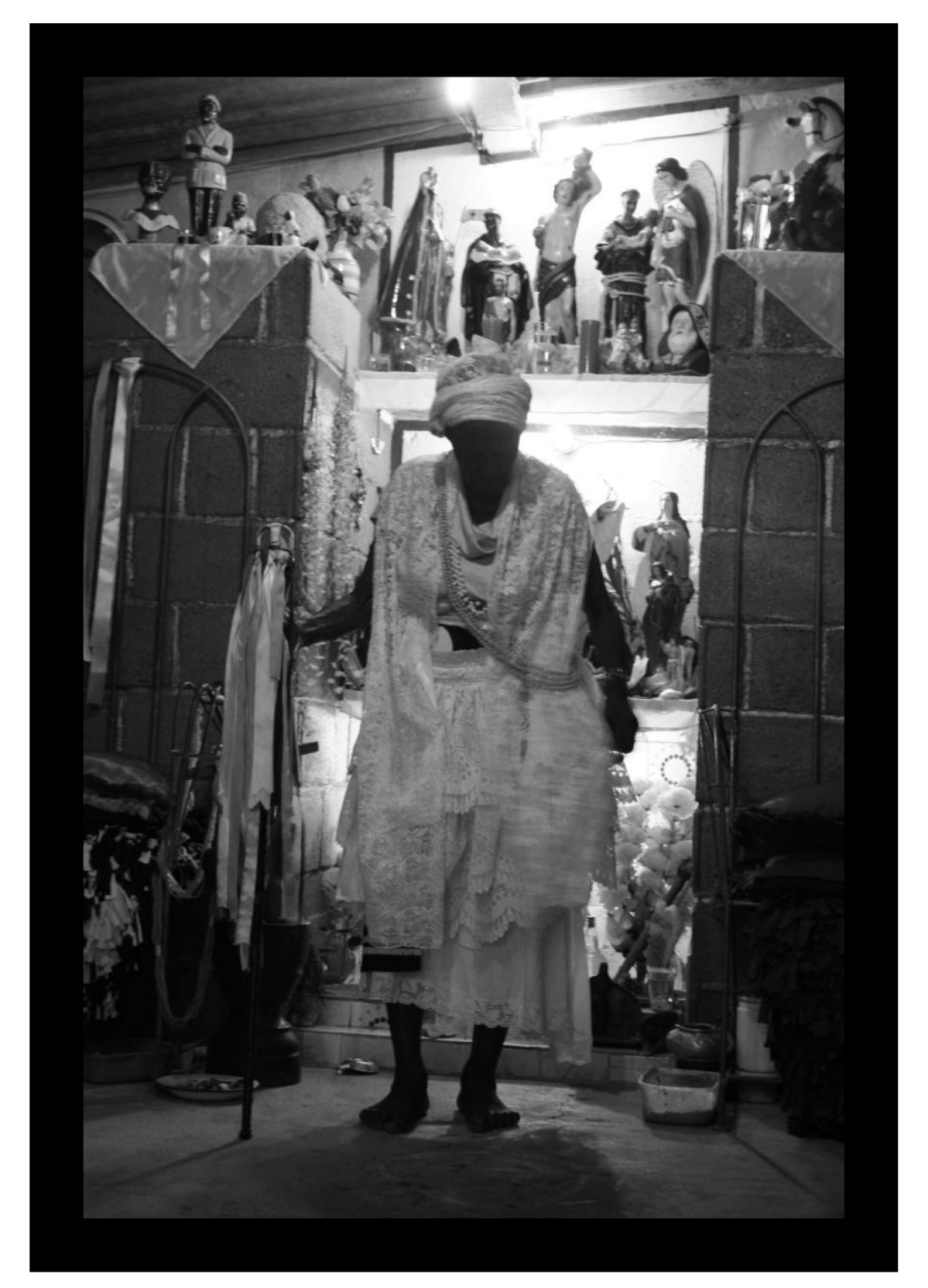




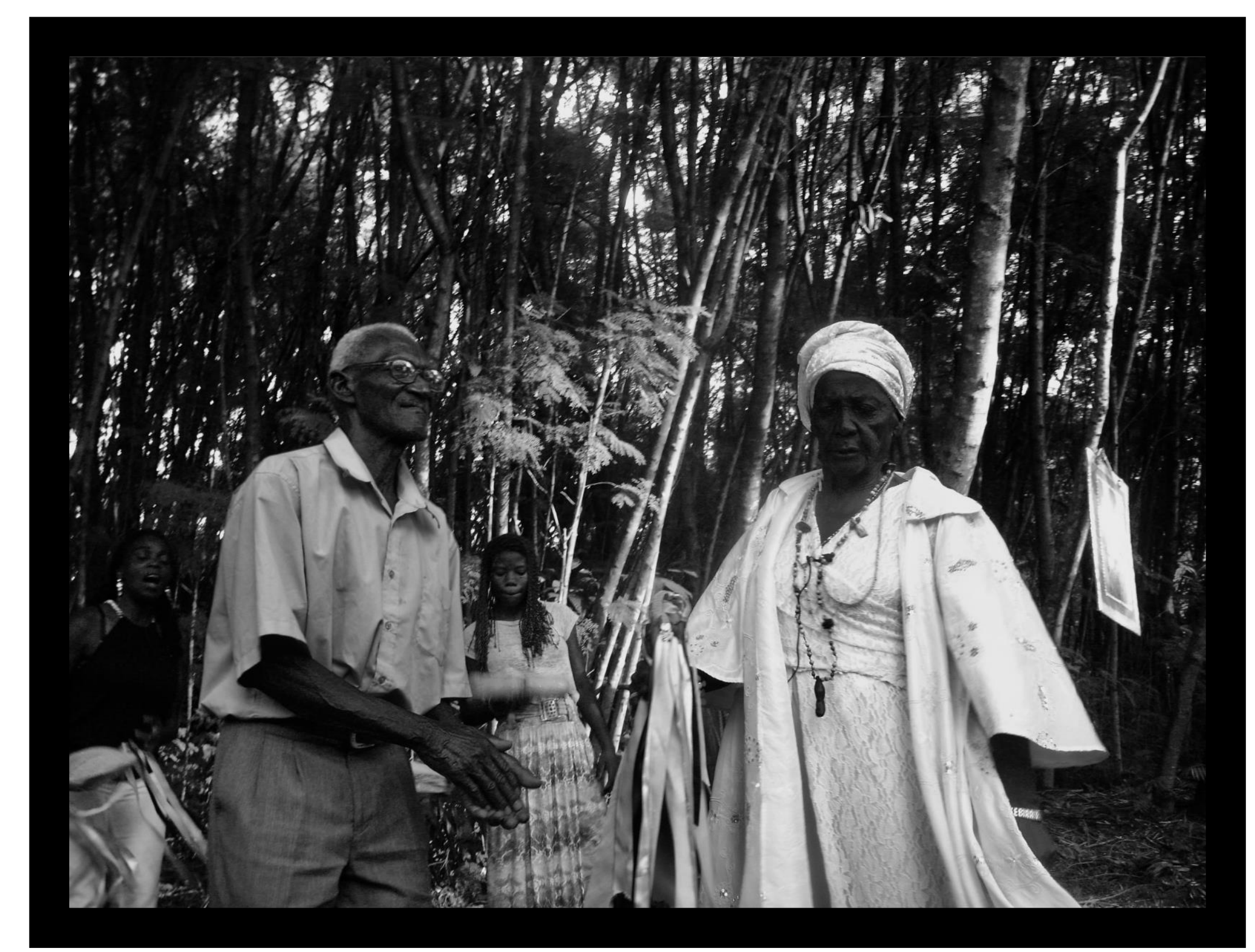




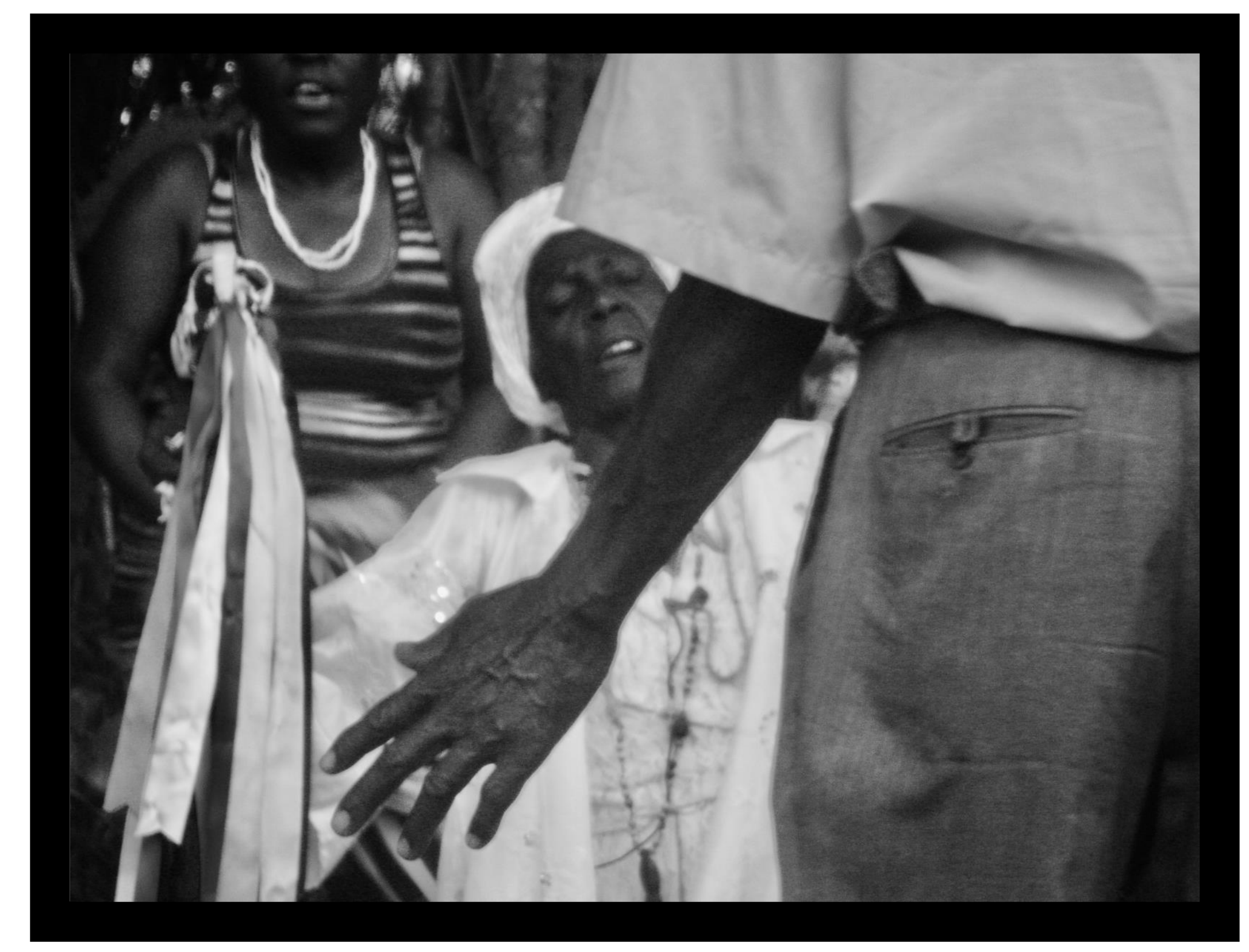




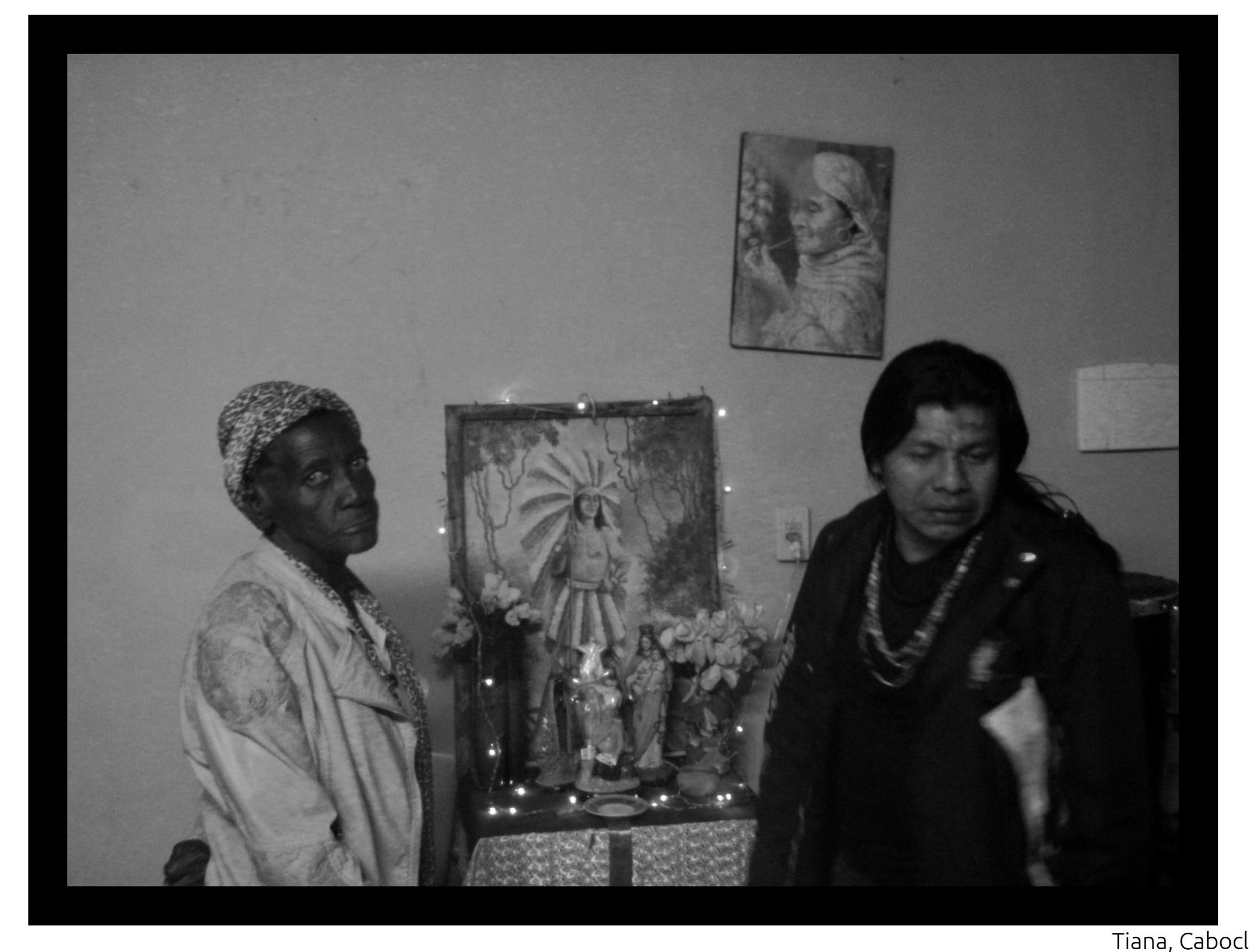




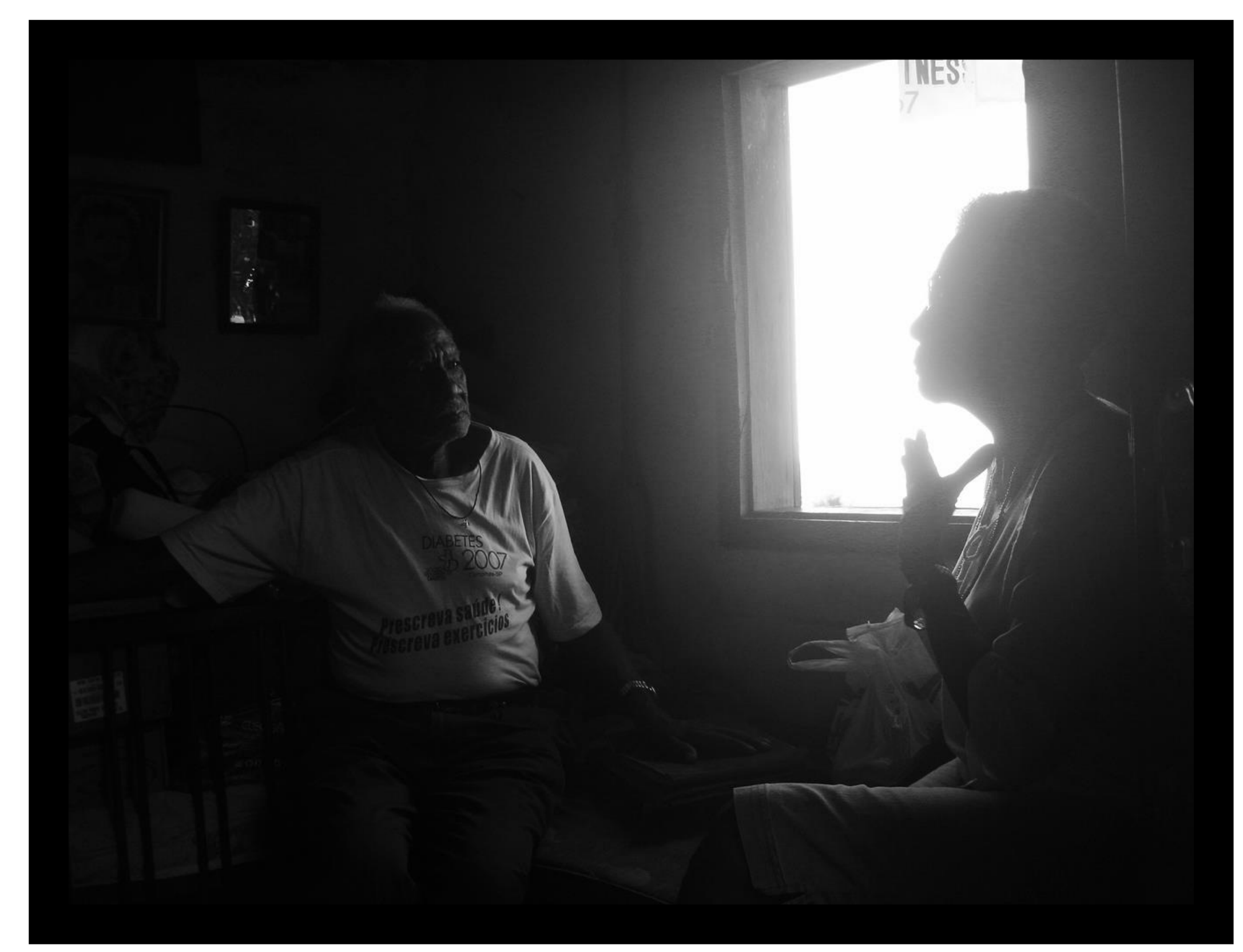




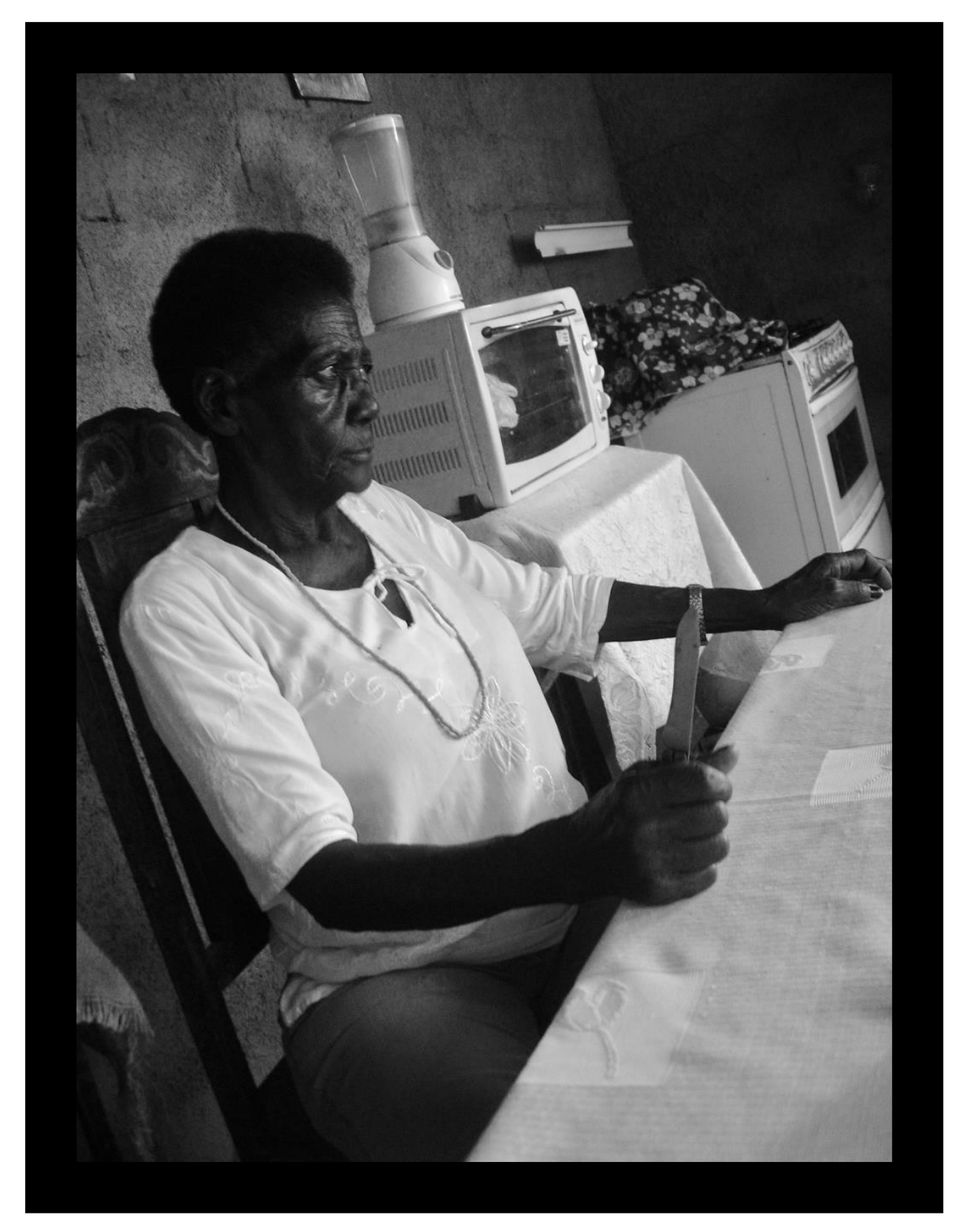




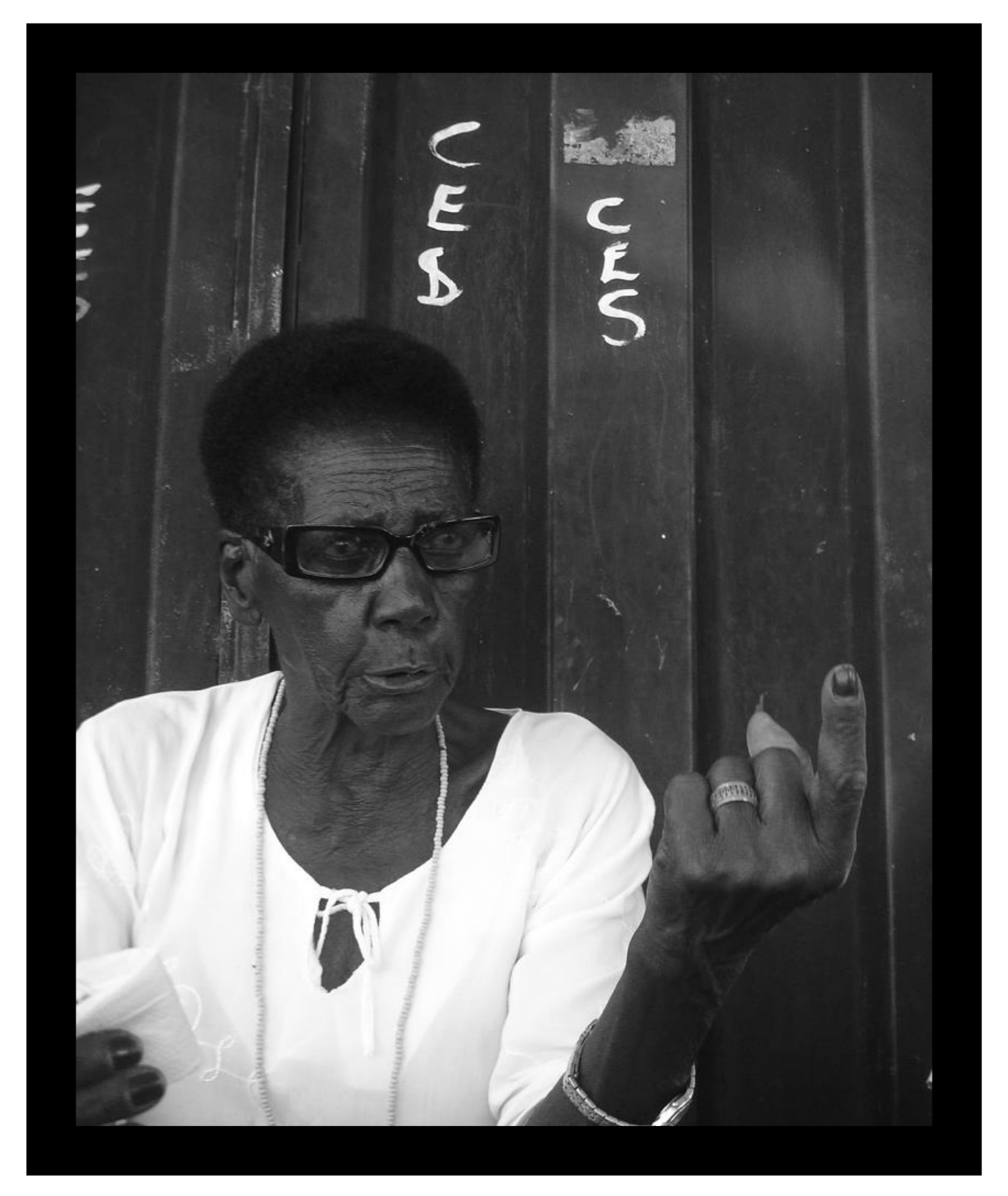




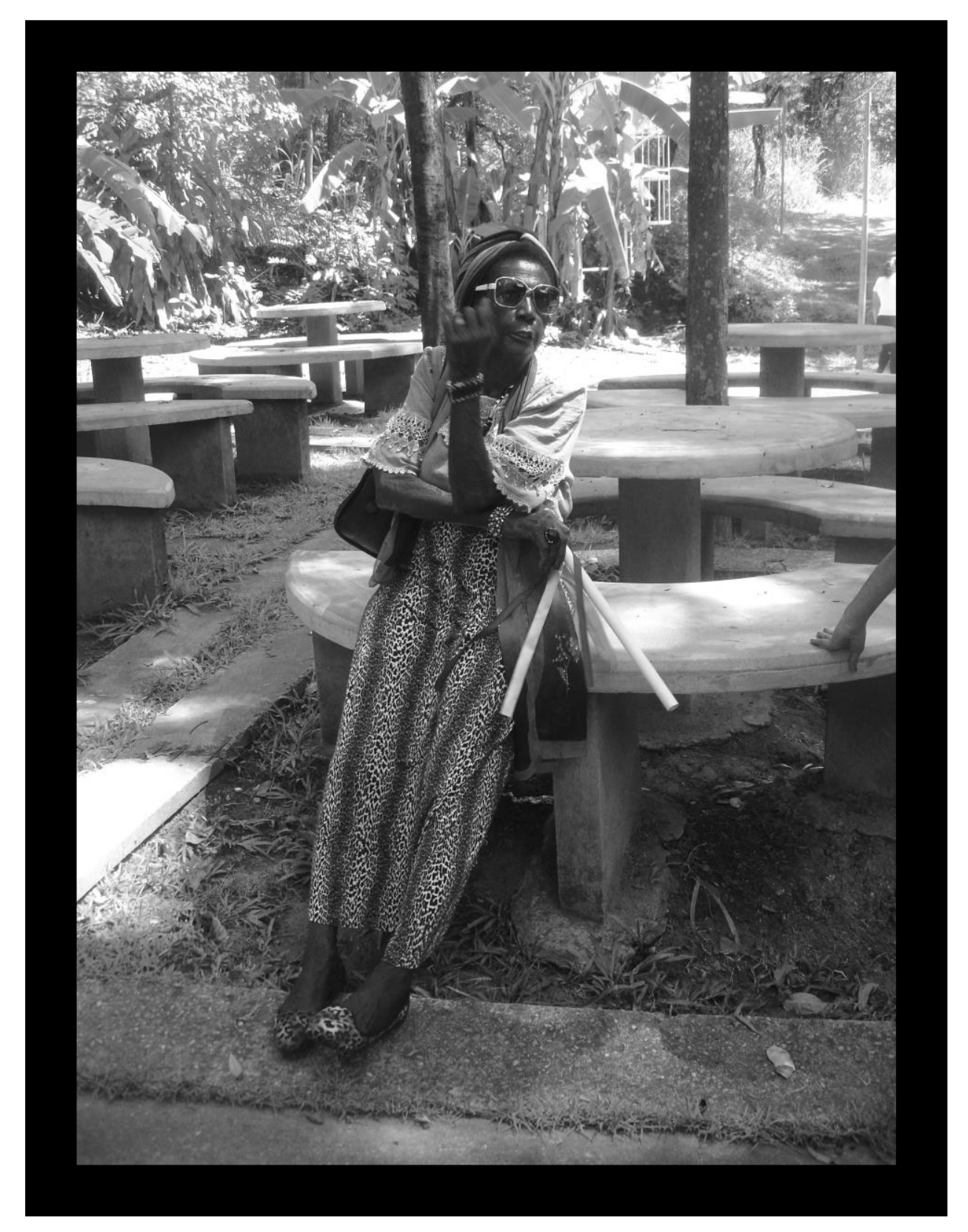




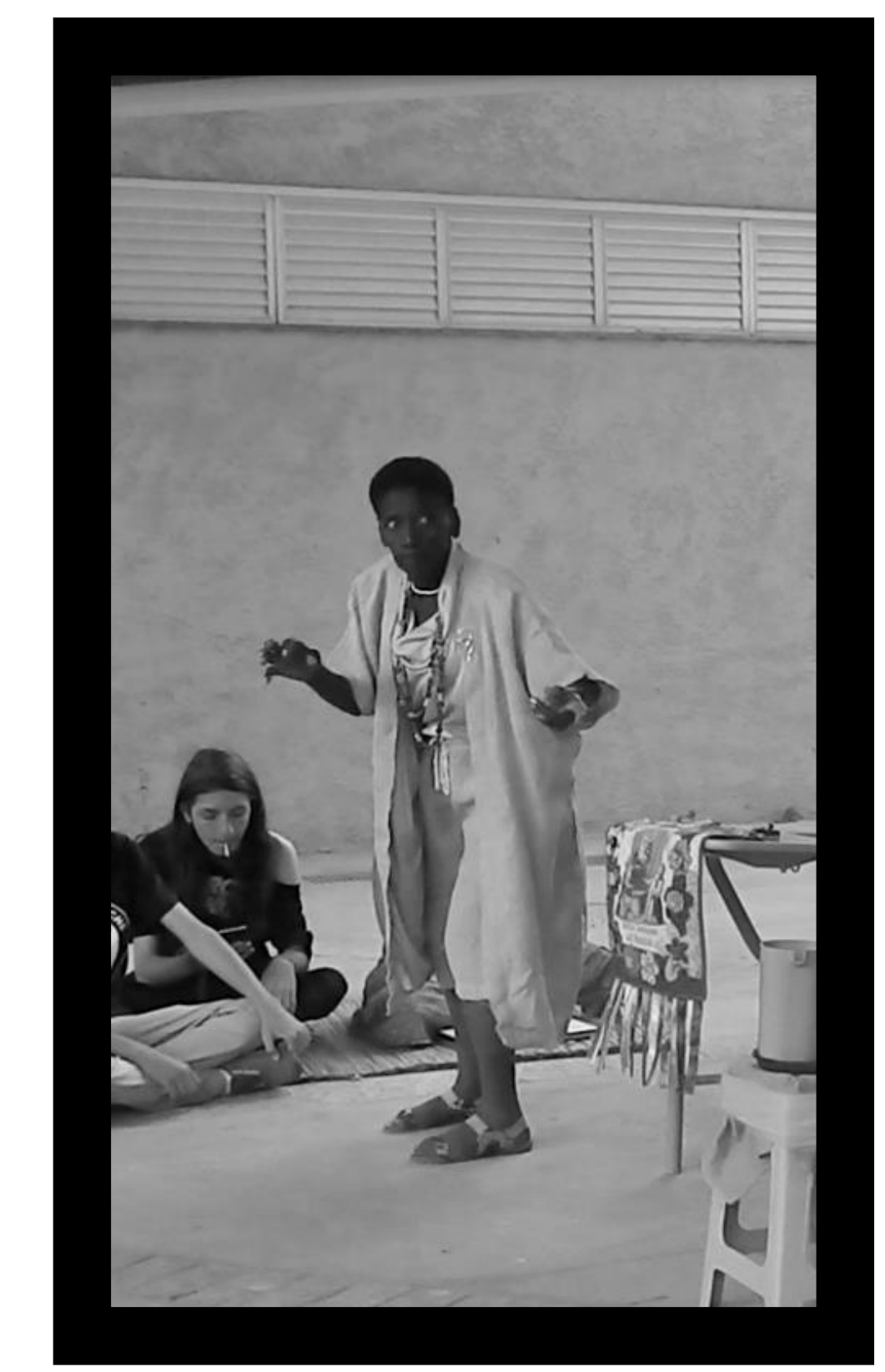




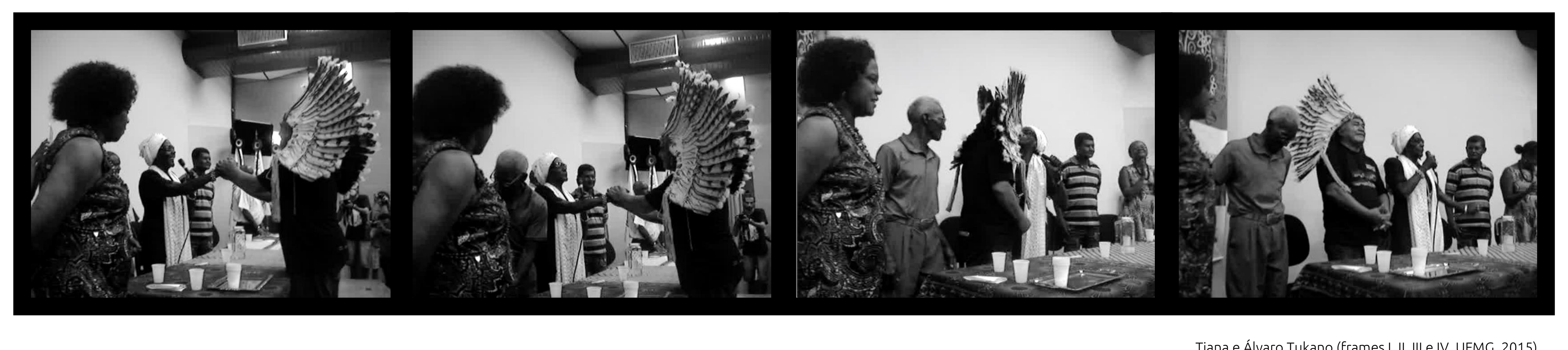




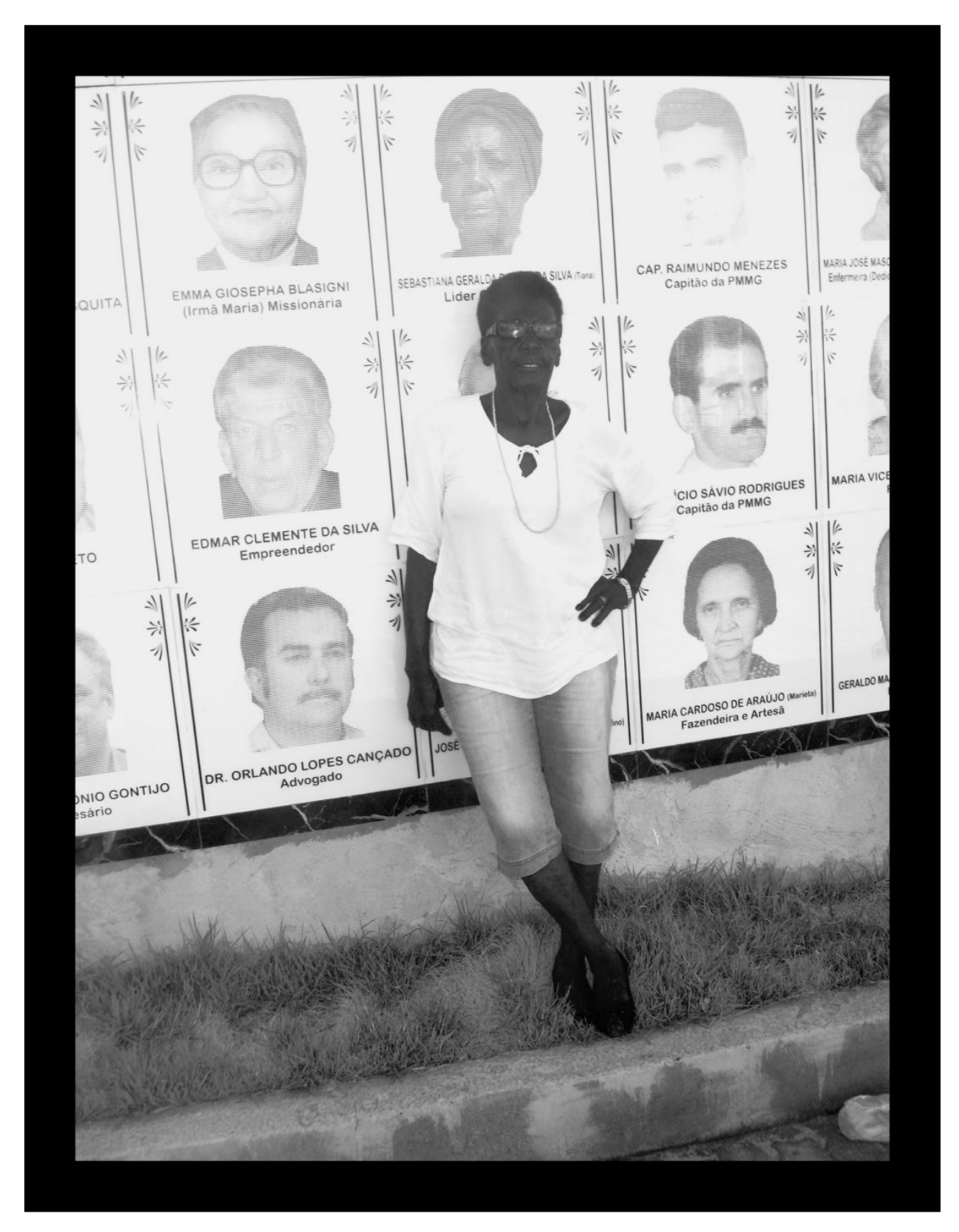




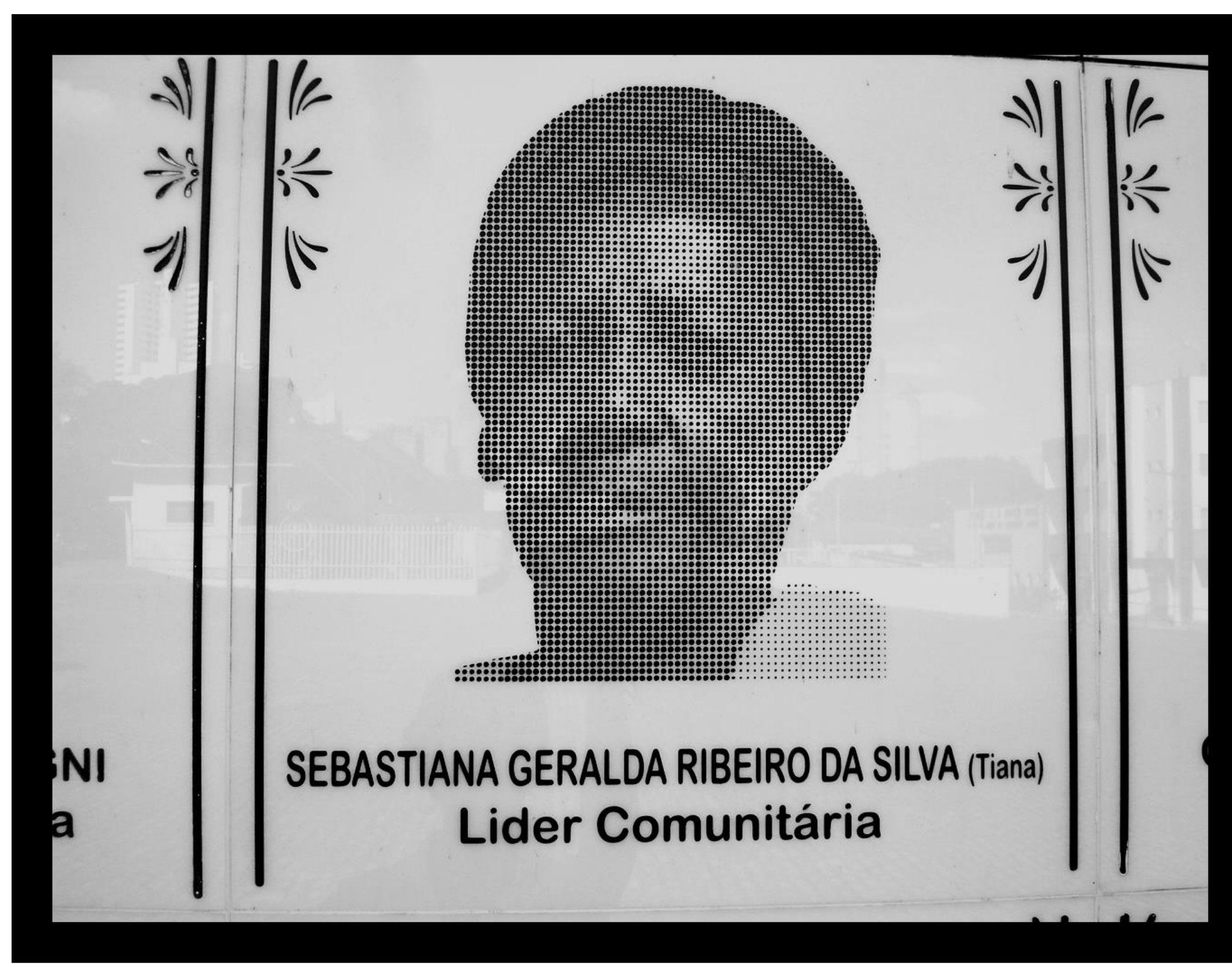




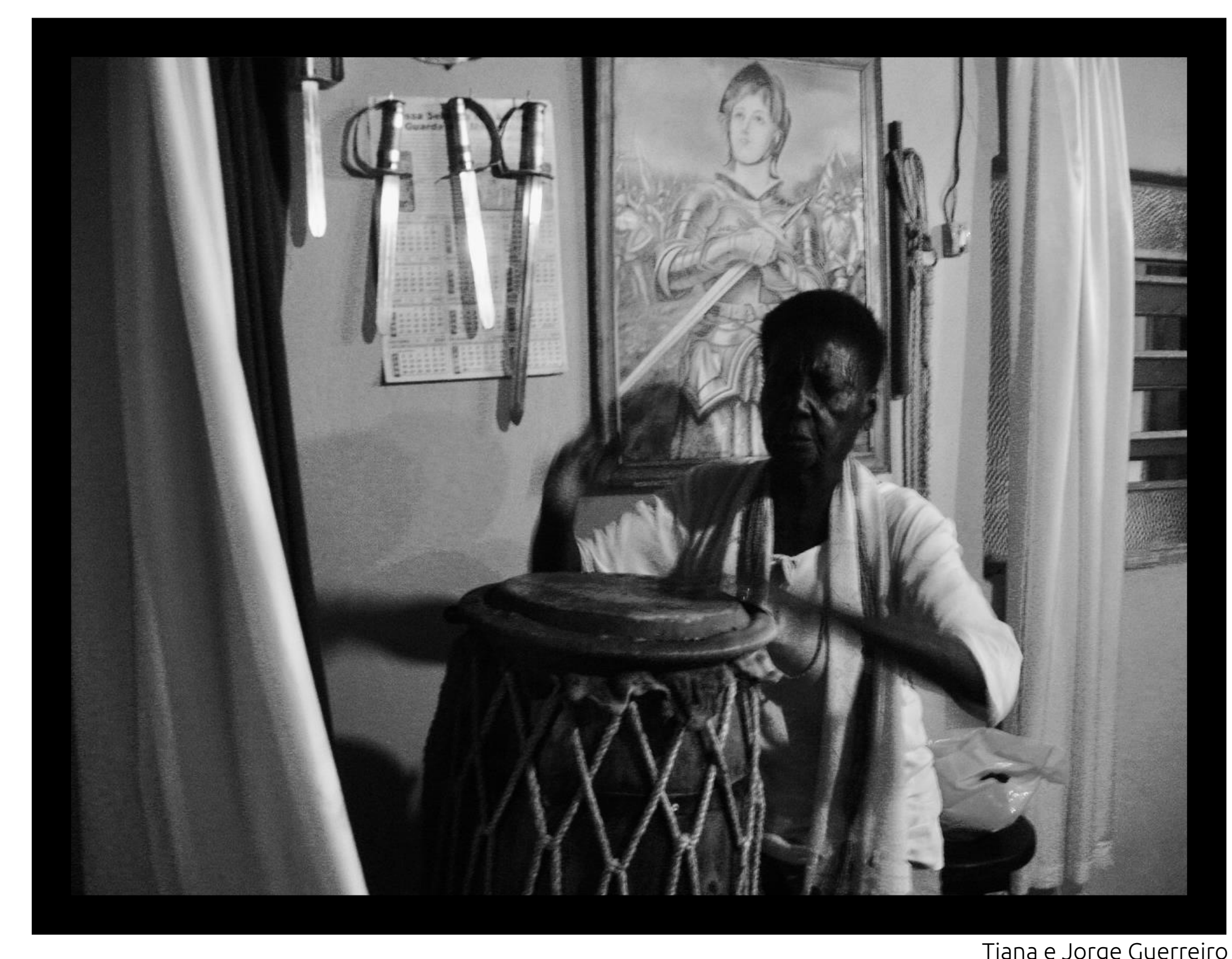




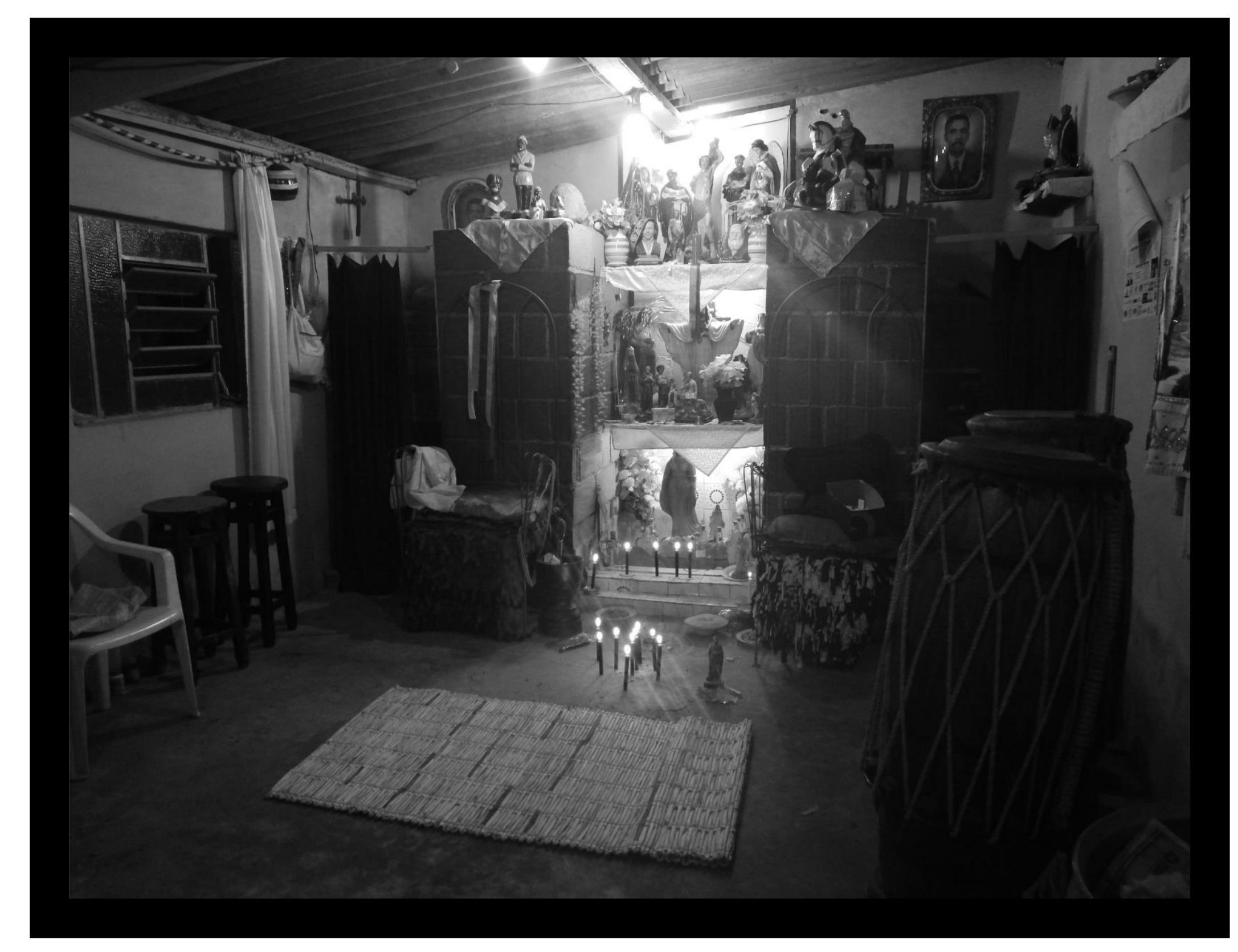


